\title{
OPINION TOWARDS INDUCED ABORTION AMONG URBAN WOMEN IN DELHI, INDIA
}

\author{
S. B. KAR \\ Department of Population Planning, School of Public Health, University of Michigan, Ann Arbor, Michigan \\ 48104, U.S.A.

\begin{abstract}
This study explores the opinion towards induced abortion as a family planning method among currently married urban women of Delhi through intensive interviews. An overwhelming majority approved it under following ranking conditions: rape, deformed offspring, and unwed pregnancy. About 80 per cent approved it for family size limitation and economic reasons. Of the variables studied, the wives' education has most significant and direct influence on approval of abortion. As compared to the women of the surveys in the U.S.A., the Indian women more frequently approved abortion for economic reasons and less frequently for the protection of the mothers' health.
\end{abstract}

\section{INTRODUCTION}

THE STUDY of opinion towards induced abortion as a family limitation method among the Indian population remains a neglected area (Agarwala [1], Geijerstam [5], Krishna Murthy [10], Mohanty [11], Rao [12], Kaur [9], Tietze [14], Husain [6]). The present study explores the opinion of currently married women towards induced abortion as a family planning method and the conditions under which they approve and disapprove of induced abortion. It also explores their opinion on the legalization of induced abortion, and the inclusion of abortion services in the family welfare clinics.

\section{Sample}

METHOD

A random sample of 300 married women currently living with their husbands within the metropolitan area of New Delhi were interviewed for the study. The respondents were predominantly Hindus $(91 \%$ ), and only about 6 per cent were illiterate. Of all wives interviewed only 3 per cent were employed. All husbands were literate and employed: 26 per cent in professional or managerial occupations; 46 per cent in clerical, sales, or medium-level occupations; and 28 per cent in unskilled, semi-skilled, or lower occupations. The educational and occupational statuses of the husbands are thus relatively higher than the corresponding national averages.

Opinions towards induced abortion were obtained through a two-step process. First, three open-ended items were used to obtain the respondents' opinions regarding: (1) whether they approved induced abortion as a family planning method; (2) the conditions under which they approved induced abortion; and (3) the conditions under which they disapproved it. Second, thirteen opinion statements, nine of which were positive and four negative, were presented. The respondents were asked to state their opinion on each item on a three-point scalc.

\section{RESULTS}

Opinion regarding induced abortion

In response to the open-ended items, 63 per cent approve abortion under one or more 
conditions. The ranking conditions for approval are: "too many children" $(42$ ", $)$ " 111 wanted pregnancy" $(12 \cdot 1 \%)$; and "threat to mother's health" $\left(11{ }^{\circ}{ }_{0}\right)$. Thirteen per cent are undecided (at the same time did not offer any reasons), and 24 per cent disapprove induced abortion as a family limitation method. The ranking conditions for disapproval are: abortion might be harmful to the mother's health $(34 \%)$; when couples had "few" children $(27 \%)$; and abortion is sinful and immoral $(14 \%)$

In response to the 13 selected conditions, an overwhelming majority of the respondents approve induced abortion as a means for family limitation [Table 1 (a) and (b)]. While 85 per cent approve abortion when both partners want it, and 63 per cent agree that abortion should be legalized, about 42 per cent consider abortion immoral [Table 1 (a) and (b)]. These inconsistencies in responses are probably because, although they are generally in favor

TADLE 1 .

CONDITIONS FOR APPROVAL AND DISAPPROVAL OF INDUCED ABORTION $(N=300)$

\begin{tabular}{|c|c|c|c|}
\hline \multirow[b]{2}{*}{ (a) Conditions for approval } & \multicolumn{3}{|c|}{ Percentages } \\
\hline & Agree & Disagree & Undecided \\
\hline \multicolumn{4}{|l|}{$\begin{array}{l}\text { If a woman becomes pregnant as a result of rape, } \\
\text { abortion should be allowed }\end{array}$} \\
\hline $\begin{array}{l}\text { Abortion should be permitted when there are indications } \\
\text { of a defective offspring }\end{array}$ & 86.7 & 6.3 & $7 \cdot i)$ \\
\hline \multirow{2}{*}{\multicolumn{4}{|c|}{$\begin{array}{l}\text { If an unmarried girl is pregnant abortion should be } \\
\text { permitted }\end{array}$}} \\
\hline & $86 \cdot 7$ & $9 \cdot 0$ & $4 \cdot 3$ \\
\hline *If both husband and wife want an abortion they should & $85 \cdot 0$ & 8.0 & -0 \\
\hline $\begin{array}{l}\text { * Couples with more children than they can support } \\
\text { should have the right to have an abortion if they want } \\
\text { it }\end{array}$ & 83.7 & $10 \cdot 3$ & $6 \cdot 0$ \\
\hline \multicolumn{3}{|l|}{ Abortion should be permitted where the pregnancy may } & 50 \\
\hline $\begin{array}{l}\text { If either of the parents is mentally ill, abortion should } \\
\text { be allowed }\end{array}$ & $81 \cdot 7$ & $10 \cdot 3$ & $8 \cdot 0$ \\
\hline $\begin{array}{l}\text { * Abortion facilities should be made available in } \\
\text { government clinics to those who want it }\end{array}$ & 77.4 & $15 \cdot 3$ & 73 \\
\hline * Abortion should be legalized in our country & $63 \cdot 0$ & $26 \cdot 7$ & $10 \cdot 3$ \\
\hline (b) Conditions for disapproval & Agree & Disagree & Undecided \\
\hline \multicolumn{3}{|l|}{$\begin{array}{l}\dagger \text { Abortion should not be permitted as a method of birth } \\
\text { control }\end{array}$} & 11.7 \\
\hline \multicolumn{3}{|l|}{ Abortion is harmful to mother's health and should not } & $7 \cdot 0$ \\
\hline \multirow{2}{*}{$\begin{array}{l}\text { Abortion is immoral and should not be allowed } \\
\dagger \text { Married couples who have abortions should be punished } \\
\text { under existing laws }\end{array}$} & $41 \cdot 7$ & $53 \cdot 0$ & $5 \cdot 3$ \\
\hline & $13 \cdot 3$ & $77 \cdot 4$ & $9 \cdot 3$ \\
\hline
\end{tabular}

* Positive attitudinal statements = agreement indicates approval of abortion primarily for family sizo limitation, not due to considerations of social or health consequences.

$\uparrow$ Negative attitudinal statements in same dimension as in items with asterisks.

Items without any symbol represent conditions of approval or disapproval due to moral, social, or health considerations. 
of induced abortion, when responding in an interview situation, they do not think about all the conditions under which abortion is desirable or undesirable. But when they are asked about their opinion towards abortion under different conditions they tend to become more cautious, use different frames-of-reference to evaluate the desirability, and consequently their responses differ. However, the fact that over 83 per cent of the respondents approve induced abortion due to economic considerations and as a matter of right of every couple indicates the overwhelming approval of induced abortion.

Although over 83 per cent approve abortion under five conditions, 70 per cent do not approve the use of induced abortion as a birth control method (Table 1). On probing, it was ascertained that the apparent discrepancy is not due to careless responses to these items. What the respondents were saying is, if a woman is already pregnant and if the pregnancy is unwanted, then abortion should be allowed. But, since there are other contraceptives, these methods should be used for birth control, and induced abortion should not replace these methods. It is significant to note that only 13 per cent of the respondents agree that couples who violate abortion laws should be punished. The results thus indicate an overwhelming approval of induced abortion as a family planning method and that abortion facilities should be included in the services provided by the clinics. The major consideration for approval of induced abortion is the number of children a couple has and whether the current pregnancy is wanted or not.

\section{Socio-economic status and opinion towards abortion}

Of all socio-economic and demographic variables studied, wives' educational status seems to have the greatest influence on the approval of induced abortion [Table 2 (a)]. The degree of approval* of abortion is significantly and directly related with the wives' educational status. A similar finding is also reported by Husain who concludes from her study of a sample of heads of households in an Indian city, "Educational status is the most important factor responsible for wide divergence of opinion" [6, p. 1779].

Since women's educational status seems to have strong influence on overall approval of induced abortion, opinions towards abortion under selected conditions have been analyzed while wives' educational status is held constant. In ten out of thirteen conditions there is overwhelming consensus of opinion (over $70 \%$; Table 1), while in the remaining three conditions (legalization, health hazard, and morality) there are somewhat lesser degrees of agreement. The influence of educational status on the responses to these three items is therefore analyzed.

The data indicate that the lower the educational status the greater the frequency of undecided responses about the desirability of legalization of abortion (Table 3). Educational status does not have a statistically significant relationship with opinion towards abortion as a health threat: however, it may be noted that higher proportions of respondents in the "medium" and "low" educational categories as compared to the "high" educational category thought that induced abortion is not harmful to the mother's health (Table 3).

Educational status has a statistically significant and interesting influence on approval or disapproval of abortion due to moral considerations. The respondents in the "high" and "low" educational status were more alike in their responses. Majorities within each of these

* The degree of approval is defined as how often one approves abortion out of a total of 13 conditions included in the interview schedule. Approval of 13-10 conditions is defined as high; 9-6 as medium; and 5 or less as low approval of abortion. 
TABLE 2(a).

Approval of abortion by wives' education

\begin{tabular}{lrcrc}
\hline & \multicolumn{3}{c}{ Education } \\
\cline { 2 - 4 } Approval & $\begin{array}{c}\text { High } \\
(35)\end{array}$ & $\begin{array}{c}\text { Medium } \\
(146)\end{array}$ & $\begin{array}{c}\text { Low } \\
(117)\end{array}$ & $x^{2}$ \\
\hline High & $74 \cdot 2$ & $63 \cdot 0$ & $41 \cdot 8$ & \\
Moderate & $20 \cdot 1$ & $22 \cdot 6$ & $35 \cdot 9$ & $16 \cdot 49$ \\
Low & $5 \cdot 7$ & $14 \cdot 4$ & $22 \cdot 3$ & \\
Total & $100 \cdot 0$ & $100 \cdot 0$ & $100 \cdot 0$ & \\
\hline
\end{tabular}

d.f. $=4 ; P<0.01$.

TABLE 2(b).

APPROVAL OF ABORTION BY SOCIAL STATUS

\begin{tabular}{|c|c|c|c|c|}
\hline \multirow[b]{2}{*}{ Approval } & \multicolumn{3}{|c|}{ Social status } & \multirow[b]{2}{*}{$x^{2}$} \\
\hline & $\begin{array}{c}\text { High } \\
(N=77)\end{array}$ & $\begin{array}{l}\text { Medium } \\
(N=139)\end{array}$ & $\begin{array}{c}\text { Low } \\
(N=79)\end{array}$ & \\
\hline High & $51 \cdot 9$ & $60 \cdot 4$ & $54 \cdot 5$ & \\
\hline Moderate & $36 \cdot 4$ & $25 \cdot 2$ & $24 \cdot 1$ & $5 \cdot 51$ \\
\hline Low & $11 \cdot 7$ & $14 \cdot 4$ & $21 \cdot 5$ & \\
\hline Total & $100 \cdot 0$ & $100 \cdot 0$ & $100 \cdot 0$ & \\
\hline
\end{tabular}

d.f. $=4 ; P>0 \cdot 10$.

sub-samples considered abortion immoral (Table 3). An overwhelming majority of respondents in the "medium" educational status, however, did not consider abortion immoral. This result suggests that the respondents with "high" and "low" educational status are relatively more traditional in moral issues relevant to abortion that those with "medium" educational status. The extent of disapproval of abortion on moral reason is nearly three times higher in the lower $(62 \%)$ than in the medium $(22 \%)$ educational status. Conversely, nearly threefourths $(73 \%)$ of the respondents in the medium as against only one-third $(33 \%)$ in the lower educational status disagreed with the statement that abortion is immoral and therefore should not be allowed. It is, however, interesting to note that the respondents with high educational status did not deviate as markedly from those in the lower educational status.

The husband's occupational status has been used to classify respondents into high. medium, and low social status. There is no statistically significant relationship between social status and approval of abortion $\left[x^{2}=5.51\right.$; d.f. $=4 ; P>0.10$ Table 2 (b)]. Although the relationship between social status and the degree of approval of abortion is not statistically significant, the proportion of low approvers of abortion (scoring 5 or less) is nearly twice as high in the "low" social status as in the "high" social status. Since the number of respondents in the "low" social strata is rather small, it is likely that in the overall analysis, this difference does not stand out significantly. However, there are indications that the higher the social status the greater is the approval of induced abortion under various conditions. It may be 
TABLE 3.

INFLUENCE OF WIVES EDUCATION ON LEGAL, HEALTH, AND MORAL CONSIDERATIONS OF INDUCED ABORTION

\begin{tabular}{|c|c|c|c|c|}
\hline \multirow[b]{2}{*}{ Opinion items } & \multicolumn{3}{|c|}{ Educational status } & \multirow[b]{2}{*}{$\chi^{2}$} \\
\hline & $\begin{array}{l}\text { High } \\
\text { (35) }\end{array}$ & $\begin{array}{l}\text { Medium } \\
\text { (146) }\end{array}$ & $\begin{array}{l}\text { Low } \\
(117)\end{array}$ & \\
\hline \multicolumn{5}{|l|}{ Abortion should be legalized } \\
\hline Agree & 60 & 69 & 57 & $9 \cdot 56^{*}$ \\
\hline Disagree & 37 & 23 & 28 & \\
\hline Undecided & 3 & 8 & 15 & \\
\hline Total & 100 & 100 & 100 & \\
\hline
\end{tabular}

\begin{tabular}{lrrrr}
\hline $\begin{array}{l}\text { Abortion is harmful to mothers' health } \\
\text { and should not be allowed }\end{array}$ & & & \\
Agree & 66 & 54 & 57 & 4.06 N.S. \\
Disagree & 23 & 40 & 35 & 8 \\
Undecided & 11 & 6 & 100
\end{tabular}

\begin{tabular}{|c|c|c|c|c|}
\hline \multicolumn{5}{|c|}{$\begin{array}{l}\text { Abortion is immoral and should not be } \\
\text { allowed }\end{array}$} \\
\hline Agree & 54 & 22 & 62 & $49 \cdot 35 \dagger$ \\
\hline Disagree & 40 & 73 & 33 & \\
\hline Undecided & 6 & 5 & 5 & \\
\hline Total & 100 & 100 & 100 & \\
\hline
\end{tabular}

$\begin{array}{lll}* P<0.05(\text { d.f. }=4) . & \text { High: } & \text { High School Graduation or above. } \\ \dagger P<0.001(\text { d.f. }=4) . & \text { Medium: } & \begin{array}{l}\text { Middle School or above, but not High School } \\ \text { Graduate. }\end{array} \\ \text { N.S. } P>0.05 . & \text { Low: } & \text { Primary or less. }\end{array}$

noted that the sample of this study was drawn from urban dwellers with higher literacy rate and, as such, even the "low" strata of the sample is socio-economically more privileged than the average rural Indian families.

\section{Opinion by previous abortions and contraception}

Of all respondents, 17 per cent reportedly experienced at least one spontaneous abortion; 9 per cent had multiple spontaneous abortions. Although the proportion of respondents with "high" approval of abortion is greater among those with previous spontaneous abortions $(68.6 \%)$ than those without $(54.2 \%)$, the relationship between previous spontaneous abortion and opinion towards induced abortion is not statistically significant $\left(\chi^{2}=\right.$ $5.86 ;$ d.f. $=22 ; P>0.05$ ). However, previous experience of induced abortion is significantly and directly related with approval of induced abortion. Of the total sample, $7 \cdot 3$ per cent reportedly practiced induced abortion. The proportion of respondents with "high" approval of induced abortion among those with previous induced abortion $(86.4 \%)$ is significantly greater than those without previous practice of induced abortion $\left(54 \cdot 3 \%, \chi^{2}=\right.$ 10.39: d.f. $=2 ; P<0.01$ ). None with previous experience of induced abortion fell in the category of "low" approval of induced abortion. 
Of all respondents, $26 \cdot 3$ per cent reportedly ever used a contraceptive method prior to the date of interview. Previous contraception is significantly related with opinion toward induced abortion $\left(\chi^{2}=8.96\right.$ : d.f. $\left.=2, P<0.05\right)$. The proportion of "low" approval of induced abortion is twice as large among those who ever used $\left(24 \cdot 1{ }^{\circ}{ }_{0}\right)$ than those who never used $(12.2 \%)$ any contraceptive. This suggests that about one-fourth of those who have eler used contraceptives are "low" approvers of abortion probably because they have reasonable faith in the effectiveness of contraceptives. It is significant that neither the number of pregnancies nor the number of living children were statistically related with the degree of approval of abortion.

\section{SUMMARY}

Three hundred currently married fertile women were interviewed within the area of metropolitan Delhi, India. The results suggest that an overwhelming majority of the respondents approved induced abortion as a family limitation method. The three top ranking conditions for approval are in the following order: pregnancy due to rape $(93 \%)$ : likelihood of deformed offspring $(87 \%)$; and unwed pregnancy $(87 \%)$. Over 80 per cent of the respondents approved abortion on economic grounds and when both spouses want to terminate an unwanted pregnancy. The majority $(77 \%)$ felt that abortion facilities should be provided by the Government family welfare clinics, and that abortion should be legalized $\left(63^{\circ}\right)$. Of all socio-economic variables, the wives' educational status was significantly related with opinion towards abortion. Previous experience of abortion and contraception were also significantly related with approval of abortion. Husbands' occupational status and parity were not related with opinion towards abortion.

\section{REFERENCES}

1. Agarwala, S. N. Abortion rate among a section of Delhi's population. Med. Digest 30, 1. 1962.

2. ANand, D. A study of abortion. Family Planning News II, 12, 1968.

3. Bhattacharjer, S. Present Trend in Liberalization of Abortion in India (Mimeo). Centrai Family Planning Institute, New Delhi, India, 1968.

4. Blake, J. Abortion and public opinion. Science 171, 540, 1971.

5. Geiserstam, G. K. An Annotated Bibliography of Induced Abortion. Center for Population Planning, University of Michigan, 1969.

6. HuSAin, I. Z. Liberalization of abortion law. Econ. Polit. Wkly 1777-1780, November, 1969.

7. JAIN, S. P. Fertility trends in greater Bombay. Sydney Conference Paper, International Union for the Scientific Study of Population, Sydney, Australia, August, 1967.

8. KantNer, J. F. American attitudes on population policy: recent trends. Studies in Family Planning, $1-7$. The Population Council, No. 30. May, 1968.

9. Kaur, S. Socio-Economic Consequences of Liberalization of Abortion. Commission 1; Paper-5. National Conference on Population Policy and Programmes, New Delhi, December, 1969.

10. Krishna Murthy, K. G. Research in Family Planning in India. Sterling Publication, Delhi, India, 1968.

11. Mohanty, S. P. A Review of Some Selected Studies on Abortion in India (Mimeo). Demographic Research and Training Center, Chembur, Bombay, India, August, 1967.

12. Rao, K. G. Studies in family planning in India: a review for programme implications, Central Family Planning Institute, New Delhi, India, 1968.

13. Rossı, A. S. Public Views on Abortion. Committee on Human Development, University of Chicago, Illinois, 1966.

14. TIETZE, C. Bibliography of Firtility Control: 1950-1965. National Committee on Maternal Health, New York: New York Publication. No. 23, 1965. 